\title{
7 IOLENCIA Y CONTROL DE LA IMAGEN. LA IDENTIDAD FEMENINA EN LA OBRA DE ANA MENDIETA
}

LUIS D. RIVERO MORENO

Universidad de Granada luisda@ugr.es

Resumen: En la sociedad de la información las imágenes de la violencia se multiplican hasta hacer complicada la posibilidad de una reflexión sobre las mismas. Esta investigación propone recuperar el trabajo de la artista Ana Mendieta como forma de afrontar la visibilización del problema de la violencia de género de un modo artístico y personal, contrapuesto al extendido desde los mecanismos del poder. De este modo, basándonos en las principales corrientes de estudios de género en contraposición a la obra de la artista cubana, se describe la posibilidad que ofrece la muestra del cuerpo y la violencia sobre el mismo a través del body art y la performan$c e$. Las mujeres alcanzan así un mecanismo de búsqueda de una identidad propia, de la creación de su imagen y de la expresión de los problemas sociales habitualmente silenciados por el poder patriarcal, empeñado en adscribirlos al ámbito privado y no visible.

Palabras clave: arte contemporáneo / body art, performance / mujeres / feminismo / violencia de género.

Abstract: In the society of information, images of violence are multiplied until they make the reflection about them complicated. This research proposes to recover the work of the artist Ana Mendieta. Her art, as opposed to the ways used by the mechanism of power, appears as a tool to face gender-based violence from an artistic and personal point of view. Thus, using the main currents of gender studies theory in contrast to the work of the Cuban artist, the possibility of the exhibition of body and violence it is described through body art and performance. Thereby, women achieve a search mechanism for identity, creating their own image and showing social problems usually silenced by the patriarchal power, engaged in ascribing them to a non visible private realm.

Key words: contemporary art / body art / performance art / women, feminism / gender violence.

\section{Introducción}

En un mundo contemporáneo dominado por los medios visuales, cualquier tema, por difícil que parezca previamente su digestión, es convertido en representación, en imagen. Presentar, o volver a presentar (en sentido estricto), el horror de la violencia es un asunto delicado y muy discutido, sobre todo en el ámbito de los medios de comunicación, habitualmente tendentes al sensacionalismo al ofrecer al espectador semejante tipo de noticias. La mostración sin más se antoja poco efectiva en el ejercicio de una posible concienciación social y política, puesto que la multiplicación de las imágenes termina por anular la reflexión y va- ciar de contenido a las mismas. Lo que Sartori denomina una "regresión cualitativa"."

En oposición, el arte se nos presenta como un modo de representación capaz de escapar de esa tendencia simplificadora y comercializadora para ofrecer un espacio de análisis independiente. Las mujeres artistas toman el control de las herramientas de generación de imágenes para ofrecernos así su visión de la violencia ejercida sobre sus cuerpos. El trabajo de la artista Ana Mendieta nos parece fundamental en la recuperación de las posibilidades del arte como método con el que afrontar la visibilización del problema de la violencia de género. Su perspectiva abierta y crítica

\footnotetext{
* Fecha de recepción: 15 de abril de 2017 / Fecha de aceptación: 13 de julio de 2017.

1 SARTORI, Giovanni, 2003, p. 56.
} 
de afrontar el tabú, lo obsceno, las raíces de la violencia y la muerte, ofrecen un punto de vista donde la representación (teatralizada) del problema, en un contexto artístico, consigue dar luz al mismo desde su base. El esfuerzo se hará pues en la tentativa de una crítica política frente a la narración unidireccional ofrecida por los mecanismos del poder.

Nuestro estudio parte de una reflexión sobre la representación de la violencia en la sociedad de la imagen. En concreto nos centraremos en las dificultades específicas asociadas a la representación de la violencia de género. A este respecto, y más allá del ámbito de los mass media, el arte se ofrece como herramienta de generación de imágenes alternativa, capaz de ofrecer una nueva visión sobre este tema. Esto será así debido a su posicionamiento más libre y alejado de los vínculos comerciales y políticos relacionados con los medios de comunicación, obviamente dependientes y continuadores de la narración dominante.

El trabajo artístico de Ana Mendieta nos ofrece así la posibilidad de análisis de una interesante vía de visibilización del horror de la violencia ejercida sobre el cuerpo de las mujeres desde muy diversas perspectivas. Afrontando decididamente la complejidad y profundidad del problema, Mendieta trata de explorar a lo largo de su carrera la violencia desde un punto de vista radical, de vuelta a la raíz, a los orígenes. Para ello traza una búsqueda personal de la identidad, de lo íntimo a lo universal. Desde ahí ofrecerá un estudio exhaustivo sobre la violencia en un sentido abierto, que abarca lo psicológico y físico, hasta llegar, como parada final, a la muerte.

El caso de Ana Mendieta es paradigmático ya que abre diversos caminos que permiten establecer relaciones en múltiples direcciones: su obra artística está inevitablemente relacionada con su propia biografía (la artista cubana moriría violentamente en extrañas circunstancias), por lo que sus representaciones, más o menos realistas o simbólicas, están estrechamente ligadas con su devenir vital como mujer y minoría étnica. Supone además un ejemplo clave de arte a rebufo de los movimientos sociales en auge en la América de los años 60 y $70 .^{2}$

La hipótesis de esta investigación plantea la posible utilización del arte, en especial el performáti- co y de acción, como vía de confrontación del problema de la violencia de género. La obra de Mendieta se ofrece así como método de afirmación de la identidad de las mujeres frente a la perspectiva pasiva y victimización ofrecida por los medios de comunicación. Se contrapone para ello su biografía con su trayectoria artística. Del mismo modo se trata de encontrar formas de enlace entre las obras directamente referidas a la violencia en la carrera de la cubana con las planteadas por otras artistas coétaneas y posteriores asociadas al movimiento feminista, estableciendo posibles paralelismos y contraposiciones.

Mendieta, en la búsqueda de una forma de comunicación alternativa a la marcada por la principalmente patriarcal de las instituciones culturales, hará un arte de guerrilla, ajeno a las pautas continuadas por la vanguardia más conocida. Un arte que se revuelve contra la concepción capitalista de la mercancía, estableciendo el propio cuerpo de la artista como materia y vehículo de expresión. Por último, este estudio va a trazar las posibles influencias y continuaciones de la vía abierta por Mendieta en décadas posteriores hasta nuestros días, no sólo en el ámbito estrictamente artístico, sino sus posibles repercusiones sociales en un sentido más general.

\section{La violencia de género y la imagen}

[...] Fotografiar es apropiarse de lo fotografiado. Significa establecer con el mundo una relación determinada que parece conocimiento, y por lo tanto poder. ${ }^{3}$

En la sociedad actual, el control de los mecanismos de creación y distribución de las imágenes es, en sí mismo, un campo de batalla. Para Virilio, en el mundo actual vivimos en una constante guerra de imágenes que, incluso, es capaz de reemplazar en gran parte a la guerra física de los objetos y sujetos. ${ }^{4}$ La producción audiovisual se sitúa así en un terreno abiertamente violento en el que los grupos de poder trazan estrategias que les permitan alcanzar objetivos políticos y económicos. Por ello las imágenes nos "bombardean" y son convenientemente seleccionadas para que lleguen en su justa dosis y secuencia a los espectadores. El objetivo último será el de moldear movimientos ideológi$\cos$ y de consumo, favoreciendo la continuación acrítica del status quo. En nuestro día a día la ima-

\footnotetext{
2 BROUDE, Norma; GARRARD, Mary D., 1996.

3 SONTAG, Susan, 2006, p. 16.

4 VIRILIO, Paul, 1989, p. 5.
} 
gen es un producto fundamental del mercado. Tal y como avisa Susan Sontag:

Aunque la cámara sea un puesto de observación, el acto de fotografiar es algo más que una observación pasiva. Como el voyeurismo sexual, es una manera de alentar, al menos tácitamente, a menudo explícitamente, la continuación de lo que esté ocurriendo. Hacer una fotografía es tener interés en las cosas tal como están, en un statu quo inmutable [...], ser cómplice de todo lo que vuelva interesante algo, digno de fotografiarse, incluido, cuando ése es el interés, el dolor o el infortunio de otra persona. ${ }^{5}$

Las imágenes violentas alimentan este juego y son consumidas con avidez. Guerra, terrorismo, accidentes..., se convierten en noticias difundidas en periódicos, televisión, internet. La carga de realidad otorgada a estas imágenes es altísima, puesto que la imagen, sobre todo la fotográfica y fílmica se ha convertido en generadora de verdad. La imagen justifica por sí misma la veracidad, la realidad de un acontecimiento. La fotografía puede ser entendida como un certificado de presencia. ${ }^{6}$

De manera contrapuesta, y en este mismo contexto, debemos tener en cuenta que la multiplicación de la imagen ha llegado a abarcar todos los ámbitos, incluido el personal e íntimo. Ante tal multiplicación de material audiovisual, los medios que lo distribuyen han reaccionado con una tendencia cada vez mayor a la espectacularidad hasta hacer de la realidad social un elemento en sí mismo reproducible como espectáculo, en todos sus aspectos, también en la violencia, sin aparente filtro ni censura. De las tesis de Debord ${ }^{7}$ a las de Baudrillard, a las de la dominación del simulacro, ${ }^{8}$ hay apenas un paso. La imagen en sí misma ha terminado por fagocitar la realidad. No hay referente más allá de lo mostrado, de lo visible en los medios. Las cosas parecen, no son.

Por ello es tan importante en la lucha social conseguir dar visibilidad a los problemas como único modo de constatar su existencia, su realidad, como único modo de certificar que efectivamente acontecen. Es aquí donde el problema de la vio- lencia de género, asumido como un hecho desde tiempos históricos remotos, ha pasado a ser un elemento de lucha, no sólo eminentemente social, de la mano de las corrientes de emancipación feminista, sino de lucha del control de la imagen.

Las teóricas feministas son conscientes de que más allá de la mera visibilización, es importante el mensaje asociado a la imagen, en sí misma ambigua. La imagen, el acto de ver, no implica conocimiento. ${ }^{9}$ La visibilización no es sin más el remedio. Y es ahí donde en los últimos decenios se ha centrado gran parte de las reivindicaciones de las defensoras de los derechos de la mujer: para conseguir atajar un problema, una injusticia social, se debe partir del origen del mismo. La continuación de la violencia contra las mujeres tiene un evidente sustrato cultural asociado a su tratamiento en el cine, televisión, revistas, así como en el arte. ${ }^{10}$ Para que la violencia sea un hecho extendido socialmente y reproducido, debemos entender que existe toda una cultura de la violencia. ${ }^{11} \mathrm{Si}$, en un primer momento el problema de la violencia de género era principalmente su ocultación, su inexistencia social al estar relegado principalmente al ámbito de lo privado, ${ }^{12}$ de la intimidad de la casa, ahora se sucederá otro mayor. Al hacerse público, al visibilizarse, el problema será el del ejercicio de control sobre la producción de las imágenes asociadas a la violencia de género. Pues si una vez públicas éstas fueran utilizadas por los grupos de poder como mero producto informativo, imagen comercial y objeto de consumo, no será posible su erradicación. Si las imágenes de la violencia de género se sitúan en un engranaje ideológico y estuctural enteramente patriarcal, no podrán oponerse al mismo. Los sistemas de representación visuales y lingüísticos se apoyan en estos mecanismos de perpetuación de la violencia ya no en un sentido físico, sino retórico y metafórico. ${ }^{13}$

\section{Un feminismo crítico}

La necesidad de un arte comprometido con la realidad social y política de su momento frente al de-

\footnotetext{
5 SONTAG, Susan, 2006, p. 28.

${ }^{6}$ BARTHES, Roland, 2009, p. 99.

7 DEBORD, Guy, 2002.

8 BAUDRILLARD, Jean, 2001.

9 SARTORI, Giovanni, 2003, p. 193.

10 DE LA CONCHA MUÑOZ, Ángeles, 2010.

11 ARMENGOL, Vicenç F., 1998.

12 GOLDFARB, Sally F., 2000.

13 DE LAURETIS, Teresa, 1985.
} 
sarrollo, en su contra, de una evolución artística formal, fría y meramente autorreferenciada, constituye uno de los debates teóricos centrales del arte desde fines del s. XIX hasta nuestros días. Si las primeras vanguardias habían forzado la fractura definitiva hacia un arte revolucionario en el sentido más amplio de la palabra, las desarrolladas tras la II Guerra Mundial tratarán de recoger y ampliar sus presupuestos de la mano de movimientos underground como el situacionismo. ${ }^{14}$ En estrecha relación con esta corriente aparecerá el movimiento hippie, el rock y la contracultura pacifista contra la guerra del Vietnam.

Como mestiza latinoamericana afincada en EE.UU., mezcla de orígenes hispanos, precolombinos y africanos, Ana Mendieta va a sentir la fuerza de la diversidad de sus orígenes. La artista va a ser una abierta defensora de la diferencia, un concepto, además, clave en la recuperación histórica del arte realizado por mujeres. ${ }^{15}$ La artista criticará así la multiculturalidad globalizadora y homogeneizadora, para defender, en oposición, la salvaguarda de las culturas más primitivas y populares en peligro. Mendieta, de este modo, obliga a una reflexión histórica que conduce a un pasado violento e imperialista siempre presente. Latinoamérica en este sentido ya había sufrido un prolongado proceso de colonización, continuado y ampliado de la mano de la globalización contemporánea, tendente a la deculturación. ${ }^{16}$ Consciente de estos mecanismos, la cubana no dudará en afirmar de forma tajante los peligros de la producción y distribución unidireccional de los mensajes:

El imperialismo norteamericano ha producido y controla los medios internacionales de comunicación e información de masas. Los bombardeos a base de información falsa y medias verdades se realizan a una escala tan grande que millones de personas viven en medio de una gran mentira. ${ }^{17}$

Por ello la artista se va a establecer como personal y complejo nexo de unión entre la cultura hegemónica occidental y la periferia explotada. Su condición de mujer y mestiza en su nuevo país de adopción le va a hacer (forzosamente) consciente de las desigualdades e injusticias que se cometen sobre las minorías. Ana Mendieta, dentro de este contexto histórico, no podía permanecer ajena a las posibilidades políticas del arte. La artista además forma parte de una generación (en que se pueden incluir Gina Pane, Hannah Wilke, Martha Rossler o Nancy Spero) con un especial interés en la crítica a la tradición oficial de la institución arte y la búsqueda de nuevas vías de expresión que dieran cabida a los problemas sociales y políticos. Debemos entender los años 70 como herederos de las revueltas de fines de los 60 y su espíritu revolucionario que coincide con la segunda ola feminista americana. ${ }^{18}$ En esos años, mientras las reivindicaciones de los grupos sociales al margen de las decisiones de poder se articulaban, el arte se posiciona como soporte de expresión y denuncia de las injusticias sufridas por mujeres, gays, negros o latinos.

Para ello Mendieta se apoyará en un discurso teórico bien estructurado, del que son reflejo sus escritos personales: Arte y política; o La lucha por la cultura, hoy en día, es la lucha por la vida. ${ }^{19}$ En ellos la artista demuestra un amplio conocimiento de la obra de autores como Levi-Strauss, Foucault, Horkheimer o Adorno.

La relación de Mendieta con el feminismo de su época es compleja y, en gran parte, contradictoria. El compromiso de la artista con el movimiento artístico feminista tiene un claro nexo de unión en el hecho de formar parte de la galería sin ánimo de lucro AIR, fundada en 1972, que tenía como principal objetivo visibilizar la obra de mujeres artistas. En su trabajo es evidente la carga de crítica al patriarcado y su concepto de mujer como objeto sexual pasivo. También lo son las relaciones que se puede establecer entre su posicionamiento y algunos elementos claves de las teorías y grupos feministas del momento. Aún así conviene señalar la singularidad de la postura de la artista cubana, en muchos aspectos crítica con el movimiento feminista mayoritario debido a su elitismo y escaso interés por la inclusión de minorías raciales.

Parece sin embargo más clara su posible relación con el ecofemenismo de d'Euabonne, una postura defensora de la naturaleza, frente a la facción mayoritaria de un feminismo que defendía la

\footnotetext{
14 NOYA MIRANDA, Francisco Javier, 1991.

15 POLLOCK, Griselda, 2003.

16 GHALIOUN, Burhan, 1998.

17 RUIDO, María, 2002, p. 87.

18 SUÁREZ BRIONES, Beatriz, 2000.

19 RUIDO, María, 2002, pp. 85-88.
} 
emancipación de la mujer de la idea esencialista de su unión con la naturaleza. ${ }^{20}$ El discurso de vuelta a lo mítico (la madre tierra, la fecundidad...) está muy emparentado con el arte de Mendieta, con su carácter pasional e irracional, con su simbología ritual y de raíz prehistórica, que relaciona la mujer con lo sagrado. ${ }^{21}$

La estrategia de la artista cubana en relación al feminismo va a ser por todo ello controvertida. En paralelo a la obra de otras artistas del momento como Carolee Schneemann, Mendieta trata de "renaturalizar" y "rematerizar" el cuerpo femenino, ${ }^{22}$ conseguir que más allá de la imagen artística, plana y aséptica, trascienda el cuerpo como elemento físico y no meramente superficial. Las obras de Mendieta son conocidas a través de documentos. Las fotografías o filmes realizados para documentar las acciones actúan como recuerdos, como herramientas intermedias que nos conectan con el hecho físico acontecido en un lugar y momento único e irrepetible.

Mendieta reclama la fisicidad del arte en un sentido que llega a ser geográfico, ${ }^{23}$ y que sólo en segunda instancia adquirirá su carácter simbólico y mágico. En ese aspecto fugaz, efímero, de lo que fue y no volverá a ser, descansa gran parte de la fuerza del arte de Mendieta, que siempre huye de la representación superficial y reclama la presentación de símbolos. El camino será el de la muestra física de algo que adquiere un valor posterior abstracto, y no el de una abstracción que remite a lo físico. Mendieta alude a lo referido de modo directo, rechazando un lenguaje racional y metafórico.

Frente a la tendencia feminista más tecnológica defendida posteriormente por autoras como $\mathrm{Ha}$ raway, ${ }^{24}$ la posición de Mendieta será completamente opuesta. La cubana no propone acabar con la distinción tradicional de género a través de las nuevas posibilidades abiertas por los nuevos medios, sino que defiende utilizarlos como mecanismo de investigación que lleven a procurar la esencia, la identidad más básica asociada a la naturaleza. Frente a las posibilidades de redefinición, Mendieta propone una arqueología (cultural y personal) que lleve a la investigación de una identidad oculta.

\section{Arte y cuerpo como herramienta política}

El arte de Ana Mendieta se nos presenta como un ejemplo muy significativo a la hora de contraponer las ideas políticas feministas con la nueva vanguardia artística surgida a partir de los movimientos sociales de finales de los años 60 y principios de los 70. Las creaciones de la artista cubana permiten enfrentar una serie de cuestiones fundamentales en el debate artístico de las últimas décadas en relación a las posibilidades de un posicionamiento político crítico frente a la norma establecida, en este caso centrado en la liberación y empoderamiento de la mujer.

Las creaciones de Mendieta muestran los diversos posicionamientos a la hora de afrontar la violencia sufrida por las mujeres desde un punto de vista político y social. Al mismo tiempo, sirven para poner en evidencia la ausencia de las mujeres en el ámbito del control de la imagen, ${ }^{25}$ su colocación al margen (marginal) de las estructuras del sistema general del arte. La posibilidad de generar un discurso sobre la violencia se convierte así, en sí misma, en algo subversivo, fuera del control de los mensajes impuestos por los mecanismos de comunicación masivos alineados con el poder patriarcal. Ana Mendieta nos ofrece a través de gran parte de sus acciones artísticas todo un catálogo de aspectos relacionados con la violencia hacia las mujeres, desde la presión física y psicológica entendida de un modo indirecto e implícito, a la muestra explícita de las consecuencias de la explotación sexual y laboral que ha llevado a las mujeres a ver reducido su cuerpo a herramienta de la que obtener un beneficio, eso sí, siempre ajeno a ellas mismas. ${ }^{26}$

La violencia se va a mostrar así como válvula de escape en una situación social de desplazamiento de la artista, mujer e inmigrante, frente a un entorno hostil. Mendieta va a utilizar la representación de la violencia como punto de partida sobre el que, por un lado, liberar su condición, de modo catárquico; y, por el otro, visibilizar de un modo

\footnotetext{
20 D'EAUBONNE, Françoise, 1974.

21 KRISTEVA, Julia, 2000.

22 GONZÁLEZ-MORENO, M. Barbaño; RIVERO MORENO, Luis D., 2017.

23 RAINE, Anne, 1996.

24 HARAWAY, Donna, 2013.

25 LEÓN, Magdalena, 2000.

26 BUTLER, Judith; LOURTIES, Marie, 1998.
} 
artístico los métodos de control y represión establecidos por el poder para modelar a los ciudadanos fuera de la norma. La artista cubana subraya así la estandarización marcada por la minoría occidental, blanca y patriarcal de la que ella misma es obvia excepción, en un ámbito aún altamente vedado en aquella época para la mujer y las culturas periféricas como el artístico.

Ana Mendieta va a realizar fundamentalmente performances y arte de acción, aunque en estrecha unión con el body art y el land art, en trabajos denominados como earth works. ${ }^{27}$ Estas corrientes se encontraban en pleno desarrollo en la década de los 70 y 80 , herederas de las tentativas anteriores de happening y fluxus, pioneras a la hora de defender la consecución de un arte radical que tenía por objetivo el establecimiento de la fusión entre arte y vida. Con ello se establecía un camino directo hacia el objetivo de acabar con la concepción de la obra como objeto-mercancía capitalista y así fulminar el entramado institucional en torno al arte. Ello apoyado en un constante proceso de desmaterialización de la obra artítisca iniciada en los años $60 .{ }^{28}$ Del mismo modo, Mendieta trató de terminar con el carácter objetual de sus creaciones. Sin embargo y para ello, se decidió por la utilización de materias básicas (tierra, agua, fuego, madera, sangre...) con una significación espiritual y mágica. En palabras de la propia Mendieta:

En arte el punto de inflexión se situó en 1972, cuando comprendí que mis pinturas no eran suficientemente reales para lo que yo quiero que transmita la imagen, y cuando digo real quiero decir que quería que mis imágenes tuvieran fuerza, que fueran mágicas. $^{29}$

La utilización no sólo de su propia imagen, del autorretrato, sino aún más, de su propio cuerpo, ahondará en la necesidad de convertir al mismo en campo de batalla político. ${ }^{30}$ La explotación laboral y comercial, la violencia ejercida desde las estructuras del poder, se materializa efectivamente en el cuerpo. Por ello el cuerpo de la mujer, tradicionalmente cosificado y comercializado, va a defenderse ahora como sujeto y ya no sólo y me- ramente objeto. El cuerpo, convertido en sí mismo en sujeto político, no será así elemento pasivo que fotografiar para convertir en imagen artística, sino un cuerpo activo utilizado por la propia artista para controlar y asumir el poder de sus acciones. $^{31}$

\section{La violencia sobre el cuerpo femenino}

Rememorando el "conócete a ti mismo" socrático, Mendieta nos propone su propia figura como campo de conocimiento sobre el que abrirse a la concepción del mundo. La utilización del cuerpo, más allá de la posible contingencia del retrato, permite una fácil identificación del espectador con la performer, pues se reconoce en sus formas. La preocupación se eleva de la identidad individual a la colectiva. Quizás por ello, el tratamiento de la imagen propia ha sido una de las constantes del arte realizado por mujeres durante el siglo $X X^{32}$ y lo que va de XXI. Mendieta subraya además su cuerpo como clara y rotundamente femenino. Las acciones que propone la artista señalan ante todo las características más visibles de la feminidad, contraponiéndolas a lo masculino. Se constata así la utilización y repetición de una simbología femenina asociada a la vulva, ${ }^{33}$ proveniente de culturas ancestrales y que también van a asumir otras artistas en aquellos mismos años: Valie Export, en 1969, había presentado Action pants. Genital panic, una obra que ahondaba en la simbología femenina, en este caso gracias a unos pantalones que, dejando un hueco a la altura de la vagina, permitían la visión de los genitales femeninos. Esa actitud de control de la imagen, unida a un posicionamiento abiertamente provocador, permitían reflexionar sobre el "miedo" a una posible rebelión de género que alterase las normas establecidas.

Volviendo a Mendieta, es en las performances de sus primeros años de carrera, en que el cuerpo de la artista aparece como protagonista, en las que trasluce más clara y directamente este tipo de mensajes feministas: Glass on body (University of lowa, 1972) y Facial Cosmetic variations (University of lowa, 1972) muestran en una serie de foto-

\footnotetext{
27 VISO, Olga; MENDIETA, Ana, 2004.

28 LIPPARD, Lucy, 1997.

${ }^{29}$ RUIDO, María, 2002, p. 89.

30 SCHERZ, Lilly W., 2002.

31 MUÑOZ-MUÑOZ, Ana M.; GONZÁLEZ-MORENO, M. Barbaño, 2014.

32 KNAFO, Danielle, 2009.

33 SCHAPIRO, Miriam; CHICAGO, Judy, 1973, pp. 11-14.
} 
grafías el rostro y cuerpo de la artista deformados configurando diferentes variantes físicas de su persona. Mendieta cuestiona la capacidad superficial de modificación de la identidad en un simple cambio estético, un camino que posteriormente desarrollaría Cindy Sherman en sus conocidos Film Stills. En el primer caso a través de un cristal que presiona las diferentes partes del cuerpo; en el segundo a través de maquillaje y pelucas; en Facial Hair Transplant (University of lowa, 1972) un amigo de Mendieta se corta la barba mientras ella la traspone a su cara. Se convierte de este modo en una "mujer barbuda", mito del horror que provocan los estados "anormales" en torno al género. ${ }^{34}$ A la artista le interesaba especialmente el valor simbólico y mágico del pelo mientras ponía en seria duda la construcción de las identidades sexuales como hecho cultural modificable más allá de lo biológico, en consonancia con la teoría foucaultiana del biopoder. ${ }^{35}$

Uno de los elementos clave a analizar en estas obras sería el de la utilización erótica de la imagen de la mujer. La mujer como imagen del deseo, tanto en la historia del arte como en la publicidad, adquiere un rol pasivo y sumiso, al dictado de la plasmación de lo imaginado y deseado por los hombres. Las artistas reflexionan pues sobre esos roles heredados, sobre una supuesta "normalidad" a la que aspirar y sus posibilidades de subversión a través de la defensa de la diferencia. De la salida de la norma se pasará posteriormente a la mostración de lo obsceno y abyecto, de lo abiertamente desagradable, escatológico y decididamente encaminado a mostrar el sexo de modo explícito y contrapuesto a su idea aséptica y erótica. $^{36}$

Mendieta, por todo ello, no busca como objetivo en sus creaciones la inserción en la cultura que le margina y niega, sino muy al contrario, un refuerzo de su alteridad. ${ }^{37}$ No pide clemencia, defiende y afirma la diferencia como única vía de escape frente al avance de la homogeneización que impone occidente. En contra de esa citada deculturación deben posicionarse las minorías, las culturas y tradiciones en peligro, con el objetivo de defender la diversidad. Su arte hace visible esta lucha desde la propia afirmación de su persona co-

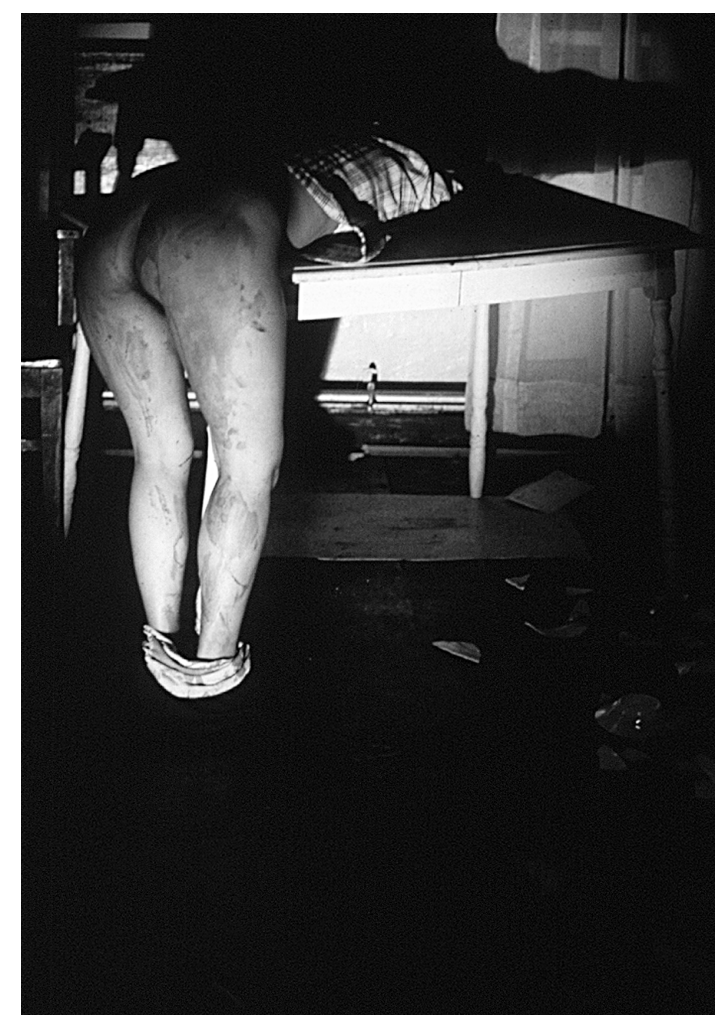

Rape Scene, 1973 (C) The Estate of Ana Mendieta Collection, L.L.C. Courtesy Galerie Lelong \& Co.

mo ejemplo de minoría, poniendo sobre la mesa el lado más oscuro de la utilización de la violencia y de la represión en manos del poder. Al mismo tiempo ofrece una revisión de las culturas primitivas como las capaces de unir de un modo más verdadero al hombre y la naturaleza, en oposición a la explotación de recursos que impone el capitalismo.

Lo obsceno, aquellos elementos ocultos y rechazados por la tradición cultural occidental, van a aparecer como materia de gran fuerza y valor simbólico en las acciones de Mendieta. La sangre va a ser quizás el elemento más utilizado, símbolo de la violencia, del dolor, de la menstruación, y al mismo tiempo el líquido indispensable que recorre nuestro cuerpo dotándolo de vida. ${ }^{38}$ Inevitablemente ésta va a aparecer en algunas de sus acciones más radicales: en Rape Scene (lowa, 1973) la artista se presenta en su propio apartamento ata-

\footnotetext{
34 BALZA, Isabel, 2011.

35 FOUCAULT, Michel, 2002.

36 BUTLER, Judith, 2011.

37 RUIDO, María, 2002, p. 39.

38 CABAÑAS, Kaira M., 1999.
} 
da sobre una mesa y semidesnuda, simulando haber sido víctima de una violación. En People looking at blood (lowa, 1973) una mancha de sangre traspasa la puerta de su casa y atraviesa la calle ante la mirada de los transeúntes.

Presenta también el vídeo Sweating blood (1973) y Untitled (self portrait with blood) (1973), una serie de fotografías en que la artista, a pesar de aparecer con el rostro cubierto en sangre, en lo que se debe suponer como un momento posterior a un acto de violencia, permanece en calma y mantiene su mirada tranquila en dirección al espectador. Así, la cubana incide en su especial interés por poner al espectador ante la difícil situación de ser testigo de esta violencia, cómplice en su silencio. Algo que hará nuevamente en Tied-up woman (University of lowa, 1973), acción que la presenta desnuda y atada de pies y manos sobre el suelo. Todas estas obras muestran de modo explícito la posición de la mujer en una sociedad que la oprime y reduce a víctima diaria de su violenta represión. También trata de explorar en ellas la dualidad público-privado, haciendo reflexionar sobre la capacidad social de mirar a aquellos problemas sociales que ocurren en ámbitos fuera de la visión. Aún más, Mendieta empodera a la mujer al ofrecer una imagen de fuerza e insumisión frente a la adversidad. No hay dolor, no hay lágrimas ni pena en su obra, enfrentada a la idea de víctima indefensa.

Por eso, estas obras permanecen tan estrechamente relacionadas como opuestas a los "pinceles humanos" utilizados por Yves Klein en sus antropometrías. Mendieta va a utilizar de nuevo su cuerpo y la sangre (simulada con pintura roja) en Body tracks (University of lowa, 1974) y Body prints (University of lowa, 1974). Estas creaciones inciden en una visión no necesariamente negativa de la sangre, que, convertida en elemento simbólico de carácter ritual y casi sacrificial, permite la vida y da fuerza. En estas enigmáticas series, el cuerpo deja su huella sobre una pared o sobre una tela (respectivamente) frente a la que se sitúa la artista. La sangre se convierte en medio de expresión, herramienta con la que plasmar mensajes de gran fuerza expresiva. Así en una de ellas, Untitled (Blood Sign \#1) "There's a Devil Inside of $M e^{\prime \prime}$ (1974), Mendieta escribe ese mensaje en la pared ante la que firma, haciendo esta vez aún más explícito un mensaje que refuerza la identi- dad propia, la alteridad frente a la norma establecida por los poderes políticos, económicos, religiosos... utilizando la idea extrema del "diablo", de nuevo lo monstruoso y rechazado, aquello que transgrede la paz social impuesta.

En todo caso, Mendieta no aparece nunca como víctima. La visualización de la sangre busca una representación no necesariamente negativa. La artista no muestra la acción que ha provocado la herida, ni tan siquiera la herida en sí misma, ni las consecuencias de tal situación, sino que construye una imagen que da fuerza, poder a la mujer, que mira desafiante al público, y no se muestra como lado débil de la balanza. La imagen de Mendieta permite construir una imagen de la resistencia, de la persistencia ante las dificultades, del poder de la identidad propia. Mendieta, valiéndose en gran parte de los avances aportados por el accionismo vienés, trata de revertir el orden fálico impuesto en el arte. ${ }^{39}$

\section{La búsqueda de los orígenes y la identidad}

El compromiso político en Mendieta se refuerza debido a su experiencia personal del desarraigo, la soledad y la marginación tras su exilio de Cuba. La artista se vio obligada a convivir con un entorno hostil sin la seguridad que otorgan la familia y la patria. Fuera de su tierra sintió la dificultad de ser mujer y componente de una minoría racial en un país de hegemonía blanca como EE.UU. Ante esas circunstancias, Ana Mendieta entendería el arte como vía hacia la recuperación de una identidad perdida. La vuelta atrás en la búsqueda de su cultura y tradición le llevó a estudiar los pueblos primitivos prehispánicos. En ellos la artista encontró la fuerza mítica y la unión del hombre con la naturaleza, temas que van a ser recurrentes en sus obras, en muchos casos conceptual, espiritual y formalmente muy próximas a estas culturas primitivas. Sus viajes periódicos a México le ayudaron a la hora de reestablecer los vínculos con el mundo latinoamericano..$^{40}$ En ellos incluso participó en excavaciones arqueológicas. Este contacto le sirvió de puente en su vuelta a la tradición afro-cubana de la que se sentía deudora.

Resulta paradójico que Mendieta formara parte de una familia burguesa acomodada y de origen en gran parte español. También lo es que su exilio, ${ }^{41}$ a pesar de las enormes dificultades que su-

39 ALIAGA, Juan Vicente, 2007.

40 RUIDO, María, 2002, p. 96.

41 BLOCKER, Jane, 1999. 
puso para ella, le abriera la posibilidad de convertirse en artista, una vía que se antoja más remota de haber permanecido en Cuba. La separación de su familia y su país, al mismo tiempo que la convertía en un ser marginal, le libertaba de las cadenas que ambas crean, dejándole vía libre en el desarrollo de una personalidad creativa, compleja y contradictoria. Su extrema situación le hace consciente del desarraigo afirmándole en la búsqueda de sus raíces.

La artista cubana va a realizar sus acciones en gran parte de los casos en parajes naturales de difícil acceso o en ámbitos privados o restringidos, de modo que en la mayoría de las ocasiones el único documento que queda de ellas van a ser películas en super 8 o fotografías de las mismas. Realizó pocas performances en lugares dedicados al arte como galerías, por lo que tan sólo algunos amigos pudieron ser espectadores de algunas de ellas. Acaba así tanto con el carácter de obra-objeto único como con el concepto de performance como espectáculo público-teatral para convertirla en un ritual de meditación y búsqueda personal. La obra ya no se prolonga en el tiempo, tan sólo quedan vestigios de ella, huellas que en gran parte de sus intervenciones la propia naturaleza en que se inserta terminará por borrar.

Ana Mendieta no tratará de imponerse a los elementos como ejercicio de dominación, al contrario, con gran respeto y casi veneración, va a procurar su unión a la naturaleza, su reinserción en ella como símbolo de la vuelta al abrigo del vientre de la madre y último contenedor del hombre tras la muerte. Los ciclos naturales están siempre presentes en sus creaciones: la vida y la muerte aparecen en continuación casi indisoluble. La muerte no se nos presenta como el fin, sino como un paso más sobre el que luego se alza de nuevo la vida, una regeneración que es visible en la naturaleza. La afirmación vital de la artista cubana nos invita a pensar en un particular "eterno retorno", un proceso de afirmación de los ritmos naturales expresados con una sensibilidad, humildad y tamaño claramente menor a las grandes intervenciones de land art planteadas por sus colegas masculinos. Para Nancy Spero, la cubana se aleja por completo de ese tipo de nuevos monumentos, de su imposición sobre el paisaje y su megalomanía:

Ana no destrozó la tierra para controlarla ni dominarla, tampoco para crear grandiosos monumentos de poder y autoridad. Ella buscó espacios íntimos y ocultos, hábitats protectores, una tregua temporal para la comodidad y la meditación. ${ }^{42}$

Una de las pocas acciones donde la artista no utilice su propio cuerpo será Feathers on a woman (University of lowa, 1972), donde actúa colocando plumas en el cuerpo de una mujer desnuda. La mujer se convierte así en gallo, símbolo masculino, mientras que tan sólo se deja al descubierto de las plumas el pubis de la modelo. Los géneros se confunden pero el carácter reproductor de lo femenino se subraya. Esta acción, junto a Death of a Chicken (University of lowa, 1972) remite ya directamente a los rituales prehispánicos y a la santería, ${ }^{43}$ un hecho que irá ganando terreno en el arte de Mendieta poco a poco. En ellas se destaca el papel de la artista que se convierte al mismo tiempo en víctima y verdugo, mujer y hombre. Esto se hace evidente en la segunda acción en que, desnuda, sujeta bocabajo a un pollo al que se acaba de cortar la cabeza. El pollo aún se agita y deja caer su sangre sobre el suelo y el cuerpo de la artista, precisamente a la altura de su pubis, rememorando la menstruación. La sangre se convierte en elemento indispensable del sacrificio ritual, elemento simbólico universal asociado a vida y muerte sobre la simbología de la sangre. ${ }^{44}$

Mutilated body on lanscape (Hotel principal, Oaxaca, 1973) supone un punto de inflexión en el arte de Mendieta, ya que resume las características de lo hecho hasta el momento y adelanta algunas de sus búsquedas posteriores: en esta acción la artista, en el suelo y cubierta con una sábana blanca sobre la que dispone un corazón, tan sólo deja suponer la silueta de un cuerpo supuestamente mutilado y del que fluye la sangre.

Las acciones de la artista van a ir acercándose de una manera cada vez más clara a los ciclos naturales. En On giving life (lowa, 1975), Mendieta se une a un esqueleto humano sobre el suelo imitando el acto sexual en una tentativa de devolver la vida a lo inerte. El carácter de la mujer como dadora de vida, como única capaz de concebir, se exalta de este modo hasta poder devolver la energía a lo muerto. En estos mismos términos conceptuales se sitúa Flowers on body (el Yagul, Oaxaca, 1973). En la acción, Mendieta aparece inmóvil sobre una tumba prehispánica, oculta por una serie de flores blancas sobre ella. El renacimiento de la vida sobre la muerte se hace evidente en la

\footnotetext{
42 RUIDO, María, 2002, p. 94.

43 LINDSAY, Arturo, 1996.

44 SZYMANEK, Angelique, 2016.
} 
naturaleza. El ser humano, aún en el último refugio tras la muerte (la tierra), bien puede servir de alimento a la vida.

El acercamiento a lo mágico y los rituales primitivos va a reforzarse además con la importancia concedida a los elementos naturales básicos (la tierra, el agua, el fuego...). La necesidad de la artista de fundirse con la naturaleza, de ser parte integrante de la misma se hará aún más fuerte en dos acciones tardías y sin título realizadas en Old Man's Creek, lowa, en 1977 y 1979 respectivamente. En ambas, Mendieta aparece cubierta de barro y restos vegetales en un intento de simbiosis con los elementos. En la primera, en pie, parece tratar de fundirse a un árbol (tradicional símbolo de vida) imitando las formas de su rugoso tronco; en la segunda, echada, se sitúa junto a un río casi camuflada entre la tierra y las ramas.

\section{La ausencia - La muerte}

El siguiente paso en la carrera de Mendieta le va a llevar a abandonar la aparición directa de su cuerpo en las acciones emprendidas. Sin embargo, en esencia, éste va a seguir presente a través de su silueta. La huella de la estancia del cuerpo sobre la tierra es ahora el motivo principal de sus creaciones. En estas obras Mendieta va a sintetizar los conceptos y objetivos de su arte hasta el momento, liberándolos del carácter más circunstancial de su presencia física explícita en la obra. Alcanza de esta manera un escalón más hacia la conceptualización y la apertura a lo universal. La unión de cuerpo y tierra se eleva a su más alto grado. La tierra como "escenario de vida" queda repleta de improntas, pistas que ayudan a entender el paso humano por ella. De ahí que nuestro conocimiento del arte se convierta casi en una acción arqueológica, de recuperación de vivencias anónimas.

En este tipo de obras, realizadas entre 1973-1980 en su mayoría, Mendieta funde de manera genial los avances derivados de diferentes corrientes para ponerlos al pleno servicio de sus ideas: body art y el land art se dan la mano en sus bodylearth works. La obra queda finalmente desmaterializada debido a su carácter efímero. De ella no quedarán más que reflejos (fotografías o vídeos) que actúan como recuerdo del recuerdo, pues la acción en sí lo que permite percibir es una huella, la silueta del cuerpo de la artista. Las obras de la cubana permanecerán visibles por poco tiempo, pues los propios elementos naturales las borrarán con facilidad.
La serie deriva directamente de sus acciones propiamente corporales y es una evolución clara de las mismas. Ya en Body tracks o Body prints habíamos visto la importancia que concede la artista a la huella humana. En este caso sin embargo ésta quedará en la naturaleza, en la tierra. Ambos elementos siempre asociados a lo femenino, siempre dadores de vida y refugio del ser humano. La ausencia del cuerpo, remite obligatoriamente a la muerte, al carácter efímero de la vida. ${ }^{45}$ La presencia se constata paradójicamente a través de la ausencia.

En la serie Siluetas Mendieta va a reforzar claramente su acercamiento a las costumbres, espíritu y formas de las culturas precolombinas. Multiplica además el carácter mágico y ritual de las acciones, en primer lugar por la utilización de la figura humana de forma simbólica y en segundo por el uso de la repetición, un elemento fundamental en el rito. Las siluetas se multiplican, se reproducen en diferentes lugares, con diferentes materiales. Casi en su totalidad aparecen Sin título y con muy diversas soluciones sobre el mismo tema: realizadas con piedras, tierra, ramas, hielo, recortadas en la hierba; en horizontal o vertical; excavadas o salientes; tan sólo algunas serán nombradas: Anima o el Entierro del Ñánigo. Poco a poco se irá imponiendo una sintetización de las formas que va a ir acercando a las obras a las formas del arte primitivo. Culminación de esta corriente va a ser la importante serie de Siluetas realizadas en la Cueva del Águila en el Parque Jaruco, cerca de La Habana, auténtico arte rupestre.

Los documentos de tales acciones sirven de espacio intermedio entre una acción pasada y los espectadores. Se marca esta distancia, este distanciamiento entre ambos. En lo que podría verse como un símbolo de la ausencia final y definitiva del cuerpo tras la muerte. El espectador nunca estará presente ni quedarán huellas físicas de las acciones, que serán engullidas por el entorno natural.

Lo funerario se impone. Tras el acto violento se sucede la constatación de la fragilidad del cuerpo y su posterior desaparición definitiva. Todo ello nos permite remitirnos de nuevo a todas aquellas mujeres, desaparecidas, ocultas por la historia, víctimas de la violencia y el olvido, y a las que Mendieta rinde tributo. ${ }^{46}$

La súbita muerte de Ana Mendieta, cargada de interrogantes, dejó una sensación de pérdida pre-

45 RUIDO, María, 2002, p. 73.

${ }^{46}$ LAPEÑA GALLEGO, Gloria, 2011. 
matura y supone además un terrible paralelismo con su propia obra artística. Su muerte violenta supone la consecución física de lo primeramente representado en sus obras: La cercanía constante de la muerte, capaz de aparecer y reducirnos a ausencia, a marca, a huella sobre los lugares que habitamos.

La figura de la artista cubana nos sirve para enfrentarnos a un hecho muy significativo en el tratamiento de las mujeres a lo largo de la historia del arte: su ausencia histórica e institucional. Mendieta sería posteriormente recuperada como ejemplo extraordinario, como merecedora de atención debido a su excepcionalidad y a su dramática biografía. El tratamiento historiográfico otorgado a la artista puede ponerse paralelo al que otorgan los medios de comunicación a las mujeres en el día a día: Las mujeres como actrices secundarias, a la sombra de las decisiones marcadas por los hombres, y sólo señaladas como víctimas: bien en lo relativo a la violencia familiar o la asociada a la explotación sexual o las desigualdades en derechos laborales. Su figura durante mucho tiempo fue relegada además a un patrón habitual a lo largo de la historia e historia del arte: el de las mujeres como parejas de hombres ilustres, ${ }^{47}$ a su sombra, en este caso como pareja de uno de los artistas más influyentes de la historia del arte del siglo XX, el minimalista Carl André.

A este respecto su figura terminó por reivindicarse con posterioridad, tal y como ocurriría en una manifestación frente al Museo Guggenheim en el Soho, Nueva York, en junio de 1992 se preguntaba "¿Donde está Ana Mendieta?". Esta reivindicación se relaciona directamente con las nuevas olas del feminismo de las últimas décadas, que en el ámbito artístico llevará a la llegada de grupos de activistas como las Guerrilla Girl o las WAC (Women's Action Coalition), que en un tono similar han tratado de hacer pública la reiterada ausencia de las mujeres artistas en las colecciones de los museos y demás ámbitos de poder de las instituciones culturales.

\section{Conclusiones}

La visibilización de la violencia realizada por Ana Mendieta a lo largo de su carrera debe ser entendida así como pionera, punta de lanza que abrió el camino a una manera directa de hacer público aquello que durante mucho tiempo fue convenientemente oculto. La influencia artística de Ana
Mendieta puede ser rastreada en la obra de artistas posteriores, tanto hombres como mujeres, desde Douglas Gordon a Regina José Galindo, que, utilizando medios similares, han actualizado gran parte de los mismos en obras que siguen denunciando la exclusión social de aquellos considerados fuera de la norma establecida y la violencia y la represión sufrida por los mismos.

El arte de la cubana propone no sólo una denuncia sino un modo de búsqueda de nuevas sensibilidades a la hora de establecer la relación del arte con el cuerpo y la naturaleza. La obra de Mendieta supone así un camino en la búsqueda de un cambio de orden, una alternativa en la representación del "otro". Estamos así ante un ejemplo de arte político y social, ajeno al devenir del objeto artístico como mercancía. Mendieta se convierte en sujeto activo que, además, reta al espectador a la hora de reflexionar sobre su posicionamiento ante este problema social. Su situación de espectador pasivo, que simplemente observa una acción violenta ocurrida en otro lugar y otro tiempo, incide en la incomodidad de una postura vouyeurística. Frente a un hecho desagradable no puede permitirse en ningún caso el placer estético. Esa difícil posición obligará a la reflexión, a la pregunta sobre qué hacer ante una situación violenta, obligando a tomar partido, a generar un espectador activo. Aún más, al presentar de modo desafiante y ambiguo el problema, Mendieta niega su posición de víctima. La artista mira fijamente al espectador y no ofrece ningún tipo de opinión, causas ni consecuencias de la situación. No hay motivo ni agente que haya causado la violencia, a la que asistimos sin mayores referencias. El compromiso social del espectador queda en entredicho, pues podría considerarse cómplice reducida su opinión a mero observador de la obra.

Mendieta consigue afrontar un asunto de vital importancia en el feminismo desde los tiempos de la segunda ola: hacer público lo privado, hacer del arte una herramienta directamente feminista, que visibilice y denuncie aspectos violentos de la sociedad o no tratados o tratados de un modo superficial por los medios.

Es importante señalar el sentido catártico, terapéutico incluso, en el que puede incidir la representación artística como modo con el que afrontar la recuperación tras sufrir la violencia. En este sentido la obra de artistas como Mendieta ofrecería una vía no sólo personal para la artista, sino

47 PERROT, Michelle, 2008. 
que serviría de posible herramienta con la que paliar las consecuencias psicológicas de las víctimas: un método con el que reforzar la autoestima y la capacidad de reflexión de las espectadoras mujeres en general, $y$, en particular, aquellas que hubieran sufrido con anterioridad la violencia de género.

La representación, la imagen ofrecida de la mujer, trata por ello de defender la individualidad, el sujeto, la identidad propia frente a la generalidad que termina por silenciar a las víctimas, reducirlas a otro número más en las estadísticas, otra referencia e iniciales en las páginas de sucesos.

Podemos afirmar que, en el contexto actual, en el que el desarrollo y multiplicación de las herramientas de creación y control de imágenes a través del uso del móvil y las redes sociales permite un uso democratizado y efectivo de las imágenes personales casi en tiempo real, se nos antoja prioritaria la necesidad de una educación audiovisual que permita a las mujeres usuarias de las mismas controlar la proyección de su imagen y la búsqueda y defensa de su identidad en semejantes circunstancias. La violencia, asumida por Mendieta como inherente al ser humano, no supone un obstáculo a la hora de afirmar la libertad del individuo, en este caso de las mujeres. Las acciones corporales de Mendieta y su documentación en forma de imagen así nos lo muestran. Con ellas se acaba con la silenciación de las víctimas y se reafirma la posibilidad de expresión de la individualidad y la identidad personal frente a las corrientes generales y dominantes, simplificadoras y ajenas a la particularidad de cada caso. El arte que muestra las injusticias y la violencia sufridas por las mujeres supone un posible punto de partida con el que reflexionar sobre las causas y consecuencias de tal situación. Además se ofrece como herramienta alternativa capaz de conformar un eficaz modo de expresión para las mujeres, permitiendo luchar contra la visión sensacionalista ofrecida desde los medios.

\section{Bibliografía}

ALIAGA, Juan Vicente. "Los pliegues de la herida: sobre violencia, género y accionismo". Artecontexto, 2005, n. 7, pp. 72-81.

ALIAGA, Juan Vicente. Orden fálico. Androcentrismo y violencia de género en las prácticas artísticas del siglo XX. Madrid: Akal, 2007.

ARMENGOL, Vicenç F. El sexo de la violencia: género y cultura de la violencia. Barcelona: Icaria Editorial, 1998.

BALLESTER, Irene. El cuerpo abierto. Representaciones extremas de la mujer en el arte contemporáneo. Gijón: Trea, 2012.

BALZA, Isabel. "Crítica feminista de la discapacidad: el monstruo como figura de la vulnerabilidad y exclusión". Dilemata, 2011, n. 7, pp. 57-76.
BARTHES, Roland. La cámara lúcida. Barcelona: Paidós, 2009.

BAUDRILLARD, Jean. Cultura y simulacro. Barcelona: Kairós, 2001.

BAYER, Betty M.; MALONE, Kareen R. "Feminism, psychology and matters of the body". Theory \& Psychology, 1996, Vol. 6, n. 4, pp. 667-692.

BEARDSLEY, John. Earthworks and Beyond Contemporary Art in the Landscape. New York: Abbeville Press. 1998.

BEST, Susan. "The serial spaces of Ana Mendieta". Art History, 2007, Vol. 30, n. 1, pp. 57-82.

BLOCKER, Jane. Where is Ana Mendieta?: Identity, performativity, and exile. Duke University Press, 1999.

BLOCKER, Jane. What the body cost: desire, history, and performance. University of Minnesota Press, 2004.

BORDO, Susan. Unbearable weight: Feminism, Western culture, and the body. Berkeley: University of California Press, 2004.

BOSCH FIOL, Esperança; FERRER PÉREZ, Victoria A.; ALZAMORA MIR, Aina. El laberinto patriarcal: reflexiones teórico-prácticas sobre la violencia contra las mujeres. Barcelona: Anthropos Editorial, 2006.

BROUDE, Norma; GARRARD, Mary D. The power of feminist art: The American movement of the 1970s, history and impact. New York: Harry N. Abrams, 1996.

BUTLER, Judith; LOURTIES, Marie. "Actos performativos y constitución del género: un ensayo sobre fenomenología y teoría feminista". Debate feminista, 1998, n. 18, pp. 296-314.

BUTLER, Judith. Bodies that matter: On the discursive limits of sex. New York: Taylor \& Francis, 2011.

CABAÑAS, Kaira M. "Ana Mendieta: Pain of Cuba, Body I Am". Woman's Art Journal, 1999, 20 (1), pp. 12-17.

CHICAGO, Judy; SCHAPIRO, Miriam. "Female imagery". En: JONES, Amelia [ed.]. The feminism and visual culture reader. London: Routledge, 2003, pp. 40-43.

DE LA CONCHA MUÑOZ, Ángeles (coord.). El sustrato cultural de la violencia de género: literatura, arte, cine y videojuegos. Madrid: Síntesis, 2010.

D'EAUBONNE, Françoise. Le féminisme ou la mort. Paris: P. Horay, 1974.

DE LAURETIS, Teresa. "The violence of rhetoric: considerations on representation and gender". Semiotica, 1985, Vol. 54, n. 1-2, pp. 11-32.

DEBORD, Guy. La sociedad del espectáculo. Valencia: Pre-textos, 2002.

FOUCAULT, Michel. Historia de la sexualidad: el uso de los placeres. Buenos Aires: Siglo XXI, 2002.

FUSCO, Coco [Ed.]. Corpus delecti: performance art of the Americas. London: Routledge, 2005.

GHALIOUN, Burhan. "Globalización, deculturación y crisis de identidad". Revista CIDOB d'afers internacionals, 1998, pp. 107-118.

GOLDFARB, Sally F. "Violence against women and the persistence of privacy". Ohio St. LJ, 2000, 61, 1.

GÓMEZ-QUINTERO, Raysa E.; PÉREZ BUSTILLO, Mireya. The female body: Perspectives of Latin American artists. Westport: Greenwood Press, 2002.

GONZÁLEZ-MORENO, M. Barbaño; RIVERO MORENO, Luis D. "Carolee Schneemann. Cine, autobiografía y poder". Revista Estudos Feministas, 2017, Vol. 25, n. 3.

HARAWAY, Donna. Simians, cyborgs, and women: The reinvention of nature. Londres: Routledge, 2013.

JONES, Amelia. Body art/performing the subject. MInnesota: University of Minnesota Press, 1998. 
KATZ, Robert. Naked by the window: the fatal marriage of Carl Andre and Ana Mendieta. New York: Atlantic Monthly Pr, 1990.

KERSTEN, Joachim. "Culture, masculinities and violence against women". British Journal of Criminology, 1996, Vol. 36, n. 3, pp. 381-395.

KNAFO, Danielle. In her own image: Women's self-representation in twentieth-century art. Madison: Fairleigh Dickinson University Press, 2009.

KRISTEVA, Julia. La mujer y lo sagrado. Madrid: Feminismos, 2000.

LAPEÑA GALLEGO, Gloria. "¿Feminismo o necesidad?: El proceso artístico en la obra de Eva Hesse y Ana Mendieta". Arte y políticas de identidad, 2011, n. 5, pp. 101-116.

LEÓN, Magdalena. "Empoderamiento: relaciones de las mujeres con el poder". Estudos Feministas, 2000, Vol. 8, n. 2, pp. 49-61.

LINDSAY, Arturo (ed.) Santeria aesthetics in contemporary Latin American art. Washington, DC and London: Smithsonian Institution Press, 1996.

LIPPARD, Lucy R. Overlay: Contemporary art and the art of prehistory. New York: Pantheon, 1983.

LIPPARD, Lucy R. Six years: the dematerialization of the art object from 1966 to 1972. Berkeley: University of California Press, 1997.

LUCIE-SMITH, Edward. Race, Sex and Gender in Contemporary Art the Rise of Minority Culture. London: Art Books, 1994.

MENDIETA, Ana. "A Selection of Statements and Notes". Sulfur, 1988, n. 22.

MENDIETA, Ana. Where is Ana Mendieta?: Identity, performativity, and exile. Durham: Duke University Press, 1999.

MEREWETHER, Charles. De la inscripción a la disolución: un ensayo sobre el consumo en la obra de Ana Mendieta. Barcelona: Fundación Antoni Tàpies, 1993.

MESKIMMON, Marsha. The Art of Reflection: Women's Self- portraiture in the Twentieth Century. London: Routledge, 1996.

MESKIMMON, Marsha. Women Making Art: History, Subjectivity, Aesthetics. London: Routledge, 2003.

MUÑOZ-MUÑOZ, Ana M.; GONZÁLEZ-MORENO, M. Barbaño. "La mujer como objeto (modelo) y sujeto (fotógrafa) en la fotografía". Arte, Individuo y Sociedad, 2014, Vol. 26, n. 1, pp. 39-54.

NOYA MIRANDA, Francisco Javier. "Por un 'situacionismo sistemico'. La teoría de sistemas sociales y el aná- lisis institucional en el estudio de los nuevos movimientos sociales". Reis, 1991, pp. 25-45.

PERROT, Michelle. Mi historia de las mujeres. Buenos Aires: Fondo de cultura económica, 2008.

POLLOCK, Griselda. Vision and Difference: feminism, femininity and the histories of art. London: Routledge, 2003.

RAINE, Anne. "Embodied geographies: subjectivity and materiality in the work of Ana Mendieta". En POLLOCK, Griselda. Generations and geographies in the visual arts: Feminist readings. London and New York: Routledge, 1996, pp. 228-252.

RUIDO, María. Ana Mendieta. Madrid: Nerea, 2002.

SARTORI, Giovanni. Homo videns: la sociedad teledirigida. Madrid: Taurus, 2003.

SCHAPIRO, Miriam; CHICAGO, Judy. "Female imagery". Womanspace Journal, 1973, vol. 1, n. 3, pp. 11-14

SCHERZ, Lilly W. Cuerpo de mujer, campo de batalla. México D.F.: Plaza y Valdés, 2002.

SONTAG, Susan. Sobre la fotografía. Madrid: Alfaguara, 2006.

SUÁREZ BRIONES, Beatriz. "La segunda ola feminista: Teorías y críticas literarias feministas". Escribir en femenino: poéticas y políticas, 2000, pp. 25-39.

SZYMANEK Angelique. "Bloody Pleasures: Ana Mendieta's Violent Tableaux". Signs: Journal of Women in Culture and Society, 2016, Vol. 41, n. 4, pp. 895-925.

TAYLOR, Diana; VILLEGAS MORALES, Juan (eds.). Negotiating Performance: Gender, Sexuality, and Theatricality in Latin/o America. Durham: Duke University Press, 1994.

VILLAPLANA RUIZ, Virginia. Nuevas violencias de género, arte y cultura visual. Murcia: Universidad de Murcia, 2008.

VILLAPLANA RUIZ, Virginia. "Formas de violencia globalizadas: género, representación y discurso". IC Revista Científica de Información y Comunicación, 2009, 6.

VIRILIO, Paul. Discurso sobre el horror en el arte. Madrid: Casimiro, 2010.

VIRILIO, Paul. War and cinema: the logistics of perception. New York: Verso, 1989.

VISO, Olga; et al. Ana Mendieta: earth body: sculpture and performance, 1972-1985. Washington: Hatje Cantz Pub, 2004.

VISO, Olga. Unseen Mendieta: The Unpublished Works of Ana Mendieta. Munich, Berlin, London and New York: Prestel, 2008. 
